\title{
Interrelationship between Indian Ocean Dipole (IOD) and Australian Tropical Cyclones
}

\author{
Kamal Kumar Saha and Saleh A. Wasimi
}

\begin{abstract}
Indian Ocean Dipole (IOD) index plays an important role in shaping the weather conditions in the Indian Ocean and surrounding areas. It has a strong correlation with Darwin pressure. This paper attempts to unfold its relationship with the occurrence of Tropical Cyclones (TCs) in the Australian basin. An analysis of 30 years' data (1976-2006) reveals that individual IOD pole (Western or Eastern) has peak negative correlation $(-.5$ and -.4 , respectively) with the seasonal occurrences of TCs in Australia. Mainly the TC occurrences in Western and Eastern sub-regions are correlated with IOD index of both the poles. Northern sub-region is more or less free from the influence of IOD index. These findings provide further insight in understanding the genesis of tropical cyclones in the Australian region.
\end{abstract}

Index Terms-TC characteristics, occurrences, relationships and genesis.

\section{INTRODUCTION}

Tropical cyclones (TCs) are major environmental hazards in Australia. The tropical parts of this country experience a number of cyclones every year. The number of occurrences varied from 6 to 13 with a mean of 11 in a TC season during the period 1976-2006. Australian TC season usually runs from the month of November to April every year. The genesis of TC is related with the overall pattern of tropical atmosphere [1]. The variation in the number of occurrences also depends on the change of behaviour of environmental parameters [2], [3]. Nicholls [4] presented the relation of Australian TC occurrences with the pressure anomaly in Darwin and proposed a procedure of predicting the number of genesis. But the accurate prediction is still an issue of extensive research.

Sea Surface Temperature (SST) in the Indian Ocean is an important factor for Australian climate. The SST differences of two small rectangle shaped areas in the Western $\left(50^{\circ}\right.$ $\left.70^{\circ} \mathrm{E}, 10^{\circ} \mathrm{S}-10^{\circ} \mathrm{N}\right)$ and Eastern $\left(90^{\circ}-110^{\circ} \mathrm{E}, 10^{\circ}-0^{\circ} \mathrm{S}\right)$ areas of tropical Indian Oceans (Fig. 1) are termed as the Indian Ocean Dipole (IOD) effects. Many scientific studies [5], [6] [7] reported that IOD has a strong impact on Australian rainfall. They specifically mentioned that warmer than average Indian Ocean SST's near Australia (negative phase of IOD events) may enhance Australian rainfall whilst cooler than average SST's (positive phase of IOD events) can result in reduced rainfall. But the total impact of IOD events in Australian climate is a potential research area as mentioned in the BOM webpage

Manusciprt received June 20, 2013; revised August 18, 2013.

The authors are with Central Queensland University, Rockhampton, Australia (e-mail: k.saha@cqu.edu.au). [http://www.bom.gov.au/watl/about-weather-and-climate/ australian-climate-influences.html?bookmark=iod]. Another important environmental index ENSO in Australian context is sometimes followed by IOD events. For example, positive phase of IOD sometimes occur during El Niño events and negative phase of IOD in La Niña events. TCs' occurrences in the Australian basin have been found to be strongly related with the periodical events of ENSO [8]. These interrelated events initiate a research loop to investigate whether there is any relationship between IOD and the occurrences of tropical cyclones in the Australian region. This is the focus of the present study.

Francis et al. [9] found that the positive phase of IOD can be activated through the occurrences of severe tropical cyclones in the Bay of Bengal. They explained that after a severe TC in the Bay of Bengal, the meridional pressure gradient along the eastern equatorial Indian Ocean (EEIO) tends to be strong with the intensification of the upwelling favourable south easterlies in Sumatra coast. At the same time water vapour reduces with the suppression of convection across EEIO. This causes extra convection over the western equatorial Indian Ocean (WEIO) and weakening of the westerlies along central equatorial Indian Ocean (CEIO). A positive dipole event could be triggered between these two events and last for a longer period than the synoptic scale. The whole procedure could sometimes occur in the region of Australian tropics and then the positive IOD event influences the occurrence of tropical cyclones.

The organisation of the paper is as follows. The second section contains the data sources and its description. Data analysis procedure and results are detailed in section three and some concluding remarks are made in the last section.

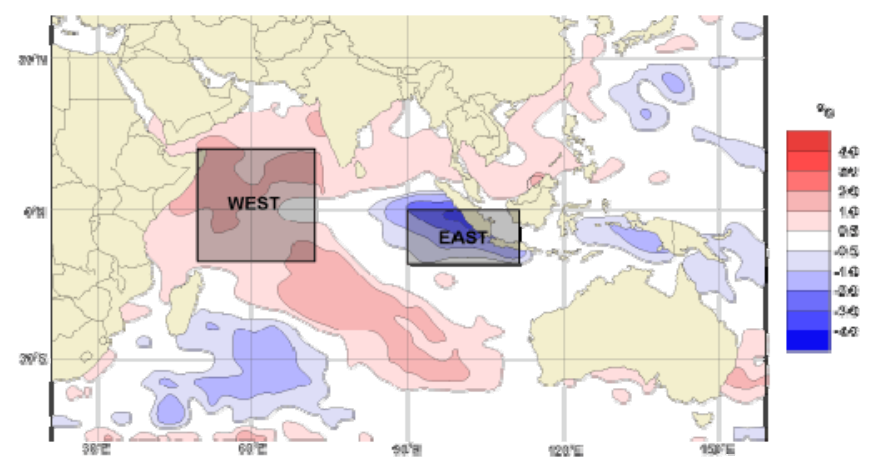

Fig. 1. Location of the East and West dipole in the Indian Ocean

\section{DAta PREPARATION AND Methodology}

TC data from the best track database of the Australian Bureau of Meteorological website has been obtained and analysed in this study. The number of occurrences of 
tropical cyclones during the period 1956-2006 has been accounted for. The Indian Dipole data has been collected from the webpage [http://www.jamstec.go.jp/frcgc$/$ research/d1/iod/sstdmi.txt]. Then a statistical correlation analysis has been performed between the number of TCs in every season with the average SSTs in individual IOD poles and the total IOD effects i.e. the SST differences between western to eastern poles.

\section{RESULTS AND DisCUSSIONS}

Australian tropical cyclone basin is divided into three sub-regions called Eastern, Northern and Western subregions. Among the three sub-regions Western sub-region produces the highest number of cyclones every year. Database used in this study reveals that about $49 \%$ of total occurrences is contributed by this sub-region. A thorough correlation analysis has been performed between the tropical cyclone occurrences during the period 1976-2006 and the Indian dipole data. Individual dipole data shows significant correlations with the overall seasonal occurrences and sub-regional occurrences of tropical cyclones in the Australian basin.

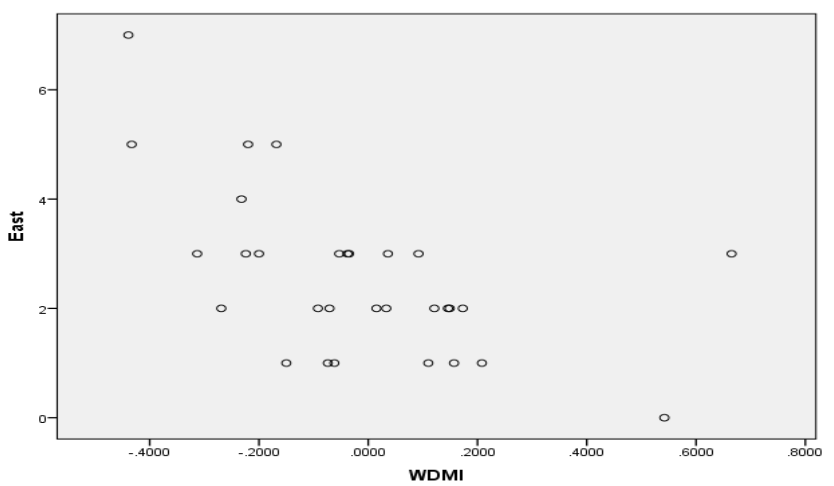

(a)

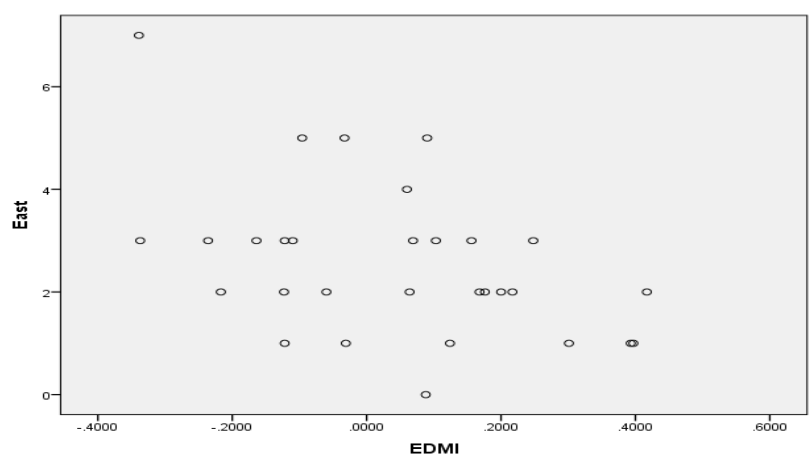

(b)

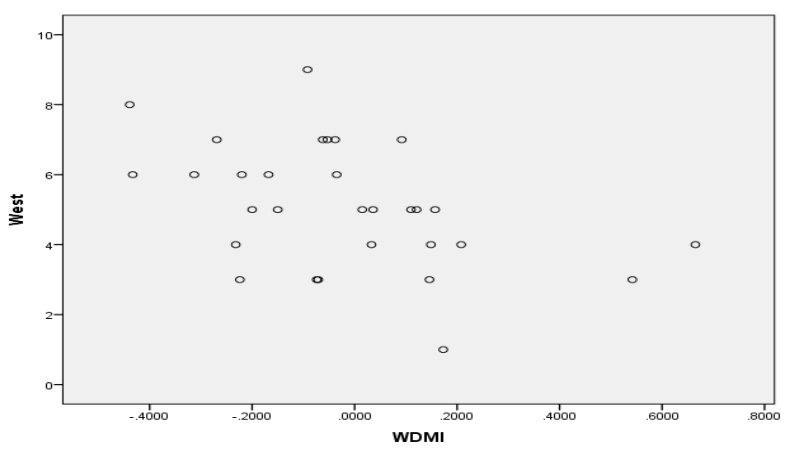

(c)

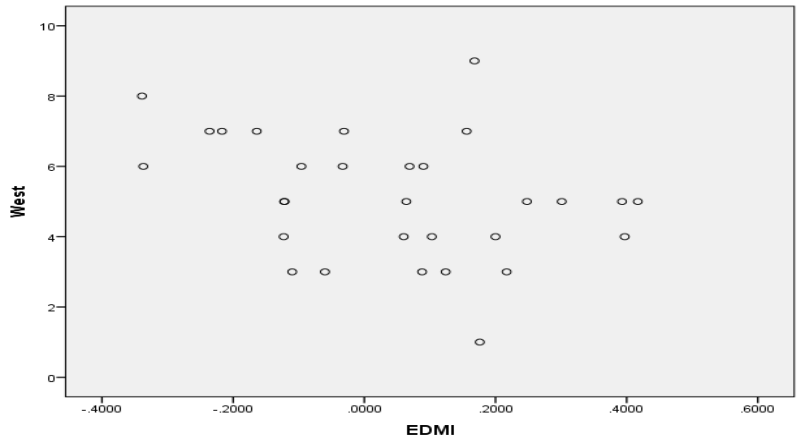

(d)

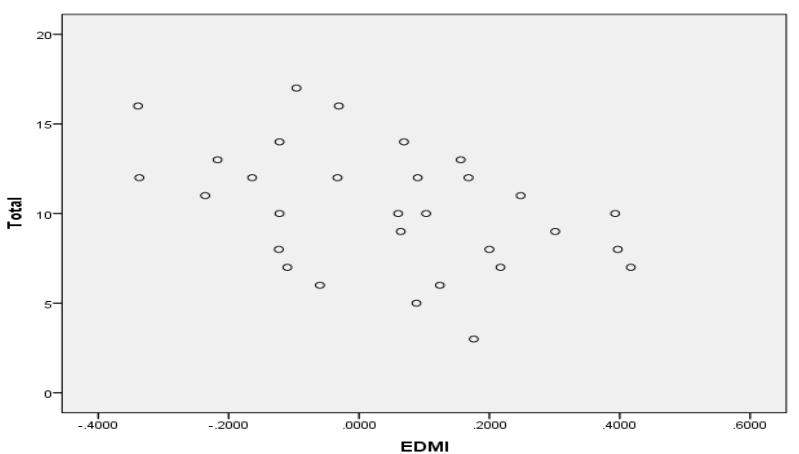

(e)

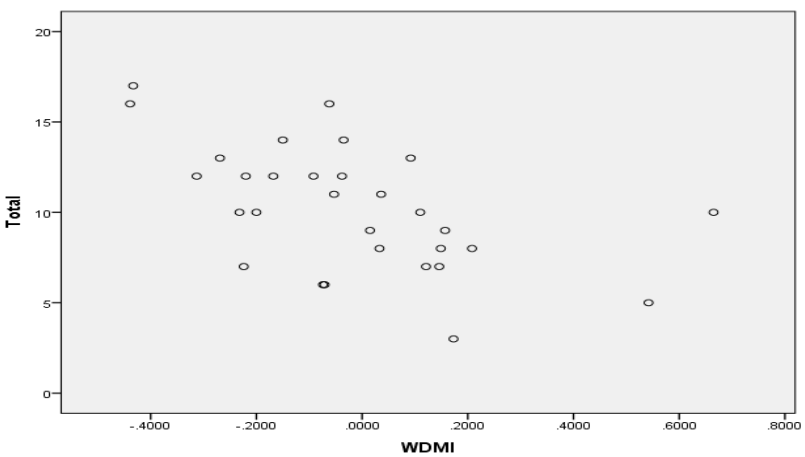

(f)

Fig. 2. Scatter-plots of number of TC occurrences for a) the Eastern subregion and Western dipole , b) the Eastern sub-region and Eastern dipole, c) the Western sub-region and Western dipole, d) the Western sub-region and Eastern dipole, e) the entire Australian basin and Eastern dipole and f) the entire Australian basin and Western dipole.

Significant relationship between individual dipole indices and the TC occurrences can be noticed in Fig. 2. Correlation coefficients have been calculated and presented in Table I below.

TABLE I: CORRELATION BETWEEN INDIVIDUAL POLE IOD AND OCCURRENCES IN SUB-REGIONS.

\begin{tabular}{llll}
\hline \hline \multirow{2}{*}{ Individual Pole IOD } & \multicolumn{3}{c}{ Sub-regions } \\
& Eastern & Northern & Western \\
\hline East DMI & $-.450^{*}$ & -0.058 & -0.342 \\
West DMI & $-.576^{* *}$ & -0.176 & $-.448^{*}$ \\
Total DMI & 0.024 & 0.143 & 0.189 \\
\hline \hline
\end{tabular}

**Correlation is significant at the 0.01 level (2-tailed).

* Correlation is significant at the 0.05 level (2-tailed).

Table I indicates that the Northern sub-region did not register any relation with the individual dipole indices. This could be caused by the land-locked feature of this sub- 
region. The land-locked feature imposes some special characteristics to the tropical cyclones which make landfall there [10]. The other two sub-regions and total dipole event showed significant negative relationships. Total occurrences of TCs are reasonably correlated with individual dipole data (Table II).

TABLE II: CORRELATION BETWEEN INDIVIDUAL POLE IOD AND TOTAL OCCURRENCES

\begin{tabular}{llc}
\hline \hline Individual Pole IOD & Correlation & Total occurrence \\
\hline EDMI & Pearson Correlation & $.447^{*}$ \\
WDMI & Pearson Correlation & $-.431^{*}$ \\
TDMI & Pearson Correlation & $-.523^{* *}$ \\
\hline \hline
\end{tabular}

The correlation between Eastern dipole SSTs anomaly for the month of October and total occurrences for the following season is .447 and in case of western dipole SST this correlation is -.431 . Both these correlations are significant at $5 \%$ level of significance. This correlation for total Indian dipole index is -.523 , which is significant at $1 \%$ level of significance. These values are presented in Table II. But the overall dipole index is more influenced by the west dipole temperature. The west dipole index influenced the larger part of the Australian basin, i.e., Western sub-region and, the whole Australian basin follow the same trend as the Western sub-region.

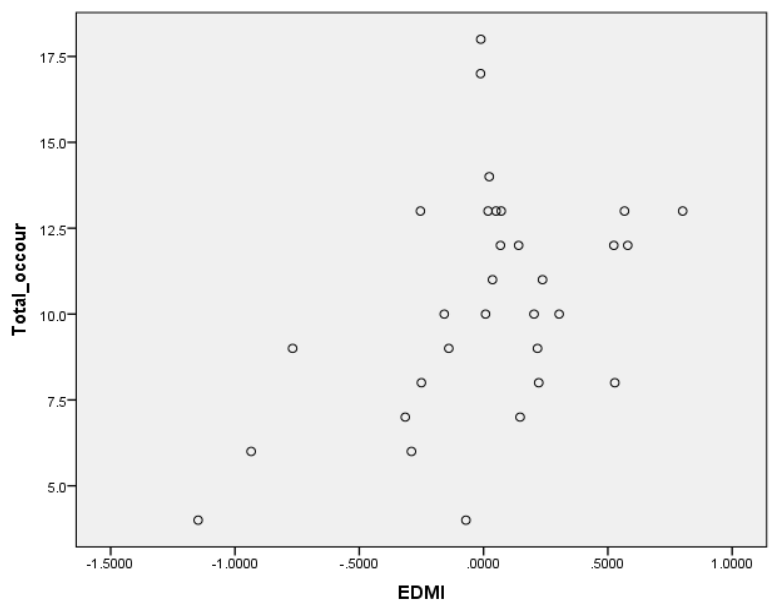

(a)

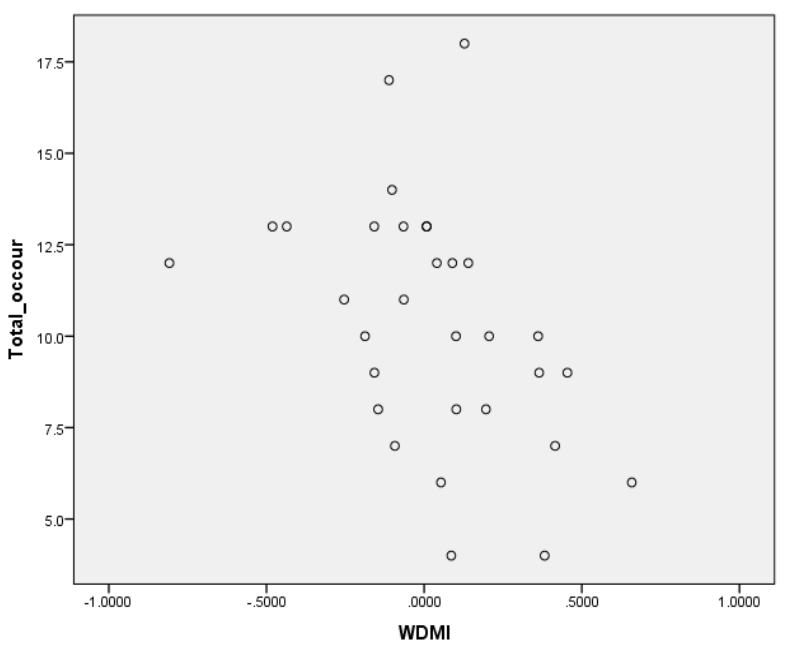

(b)

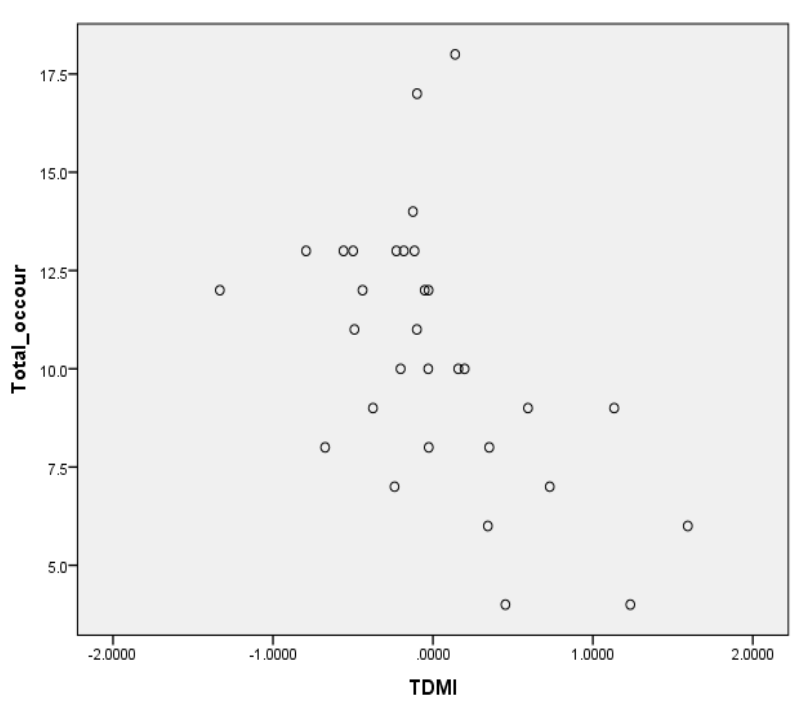

(c)

Fig. 3. Scatter-plots showing correlation between a) Previous month's Eastern dipole and total Australian basin occurrences of tropical cyclones, b) Previous month's Western dipole and total occurrences of tropical cyclones, c) Previous month's overall dipole and total occurrences of tropical cyclones.

The graphs in Fig. 3 capture the relationships between previous month's DMI values for individual dipole and overall TC occurrences in the Australian basin. It is important to note that Eastern and Western pole DMI shows complete inverse trend of relationship whereas total DMI supports the trend of western pole DMI. This phenomenon indicates the importance of western pole DMI in predicting the TC occurrences in the Australian basin.

In Table III the correlation values of number of occurrences of TCs with EDMI, WDMI and TDMI for each month within a cyclone season are presented, whereas in Table IV the correlation values are with the number of TCs that lags other parameters by one month.

For Table III the correlations are calculated for the same month's SST anomalies of the individual dipole areas and TC occurrences in different sub-regions. These results are useful for an insight but have no predictive capability. By contrast, Table IV has a lead time of one month. The results show some promise for improving the prediction of seasonal $\mathrm{TC}$ occurrences in the Australian context.

Correlation analysis between monthly dipole and occurrences in the same month within a season establishes the continuity of relationships as described above. The predictive capability as with any statistical analysis should be considered with an appreciation of the variability and uncertainty. Instead of coming up with any confidence interval or significance levels, the raw values are presented in Table IV to have a first-hand look as to how they vary.

\section{CONCLUSIONS}

The importance of Indian Ocean Dipole Index for the Australian climate hitherto has been well known only in relation to rainfall. According to the Australian Bureau of Meteorology's website it is assumed that IOD might have potentiality to predict the tropical cyclones as well. The present study is an initiative to investigate the potentiality of IOD-Australian tropical cyclones association. 
TABLE III: CORRELATION BETWEEN NUMBERS OF TC OCCURRENCES AND SAME MONTH DMIS WITHIN A SEASON

\begin{tabular}{|c|c|c|c|}
\hline TC Season & EDMI & WDMI & TDMI \\
\hline 1976 & -0.51 & 0.24 & 0.65 \\
\hline 1977 & 0.26 & -0.84 & -0.57 \\
\hline 1978 & -0.30 & 0.48 & 0.68 \\
\hline 1979 & -0.34 & 0.82 & 0.87 \\
\hline 1980 & -0.40 & -0.41 & 0.31 \\
\hline 1981 & -0.44 & -0.14 & 0.44 \\
\hline 1982 & 0.92 & -0.60 & -1.00 \\
\hline 1983 & -0.42 & -0.90 & -0.71 \\
\hline 1984 & -0.20 & -0.57 & -0.23 \\
\hline 1985 & 0.24 & -0.52 & -0.48 \\
\hline 1986 & -0.98 & 0.36 & 0.99 \\
\hline 1987 & -0.45 & 0.79 & 0.60 \\
\hline 1988 & -0.58 & -0.09 & 0.81 \\
\hline 1989 & -0.57 & 0.30 & 0.89 \\
\hline 1990 & 0.11 & 0.34 & 0.33 \\
\hline 1991 & 0.17 & -0.76 & -0.63 \\
\hline 1992 & -0.05 & 0.60 & 0.68 \\
\hline 1993 & -0.30 & -0.06 & 0.14 \\
\hline 1994 & 0.80 & -0.08 & -0.61 \\
\hline 1995 & -0.84 & 0.65 & 0.88 \\
\hline 1997 & 0.33 & 0.16 & -0.35 \\
\hline 1998 & 0.06 & -0.25 & -0.16 \\
\hline 1999 & 0.69 & -0.37 & -0.09 \\
\hline 2000 & 0.90 & -0.62 & 0.41 \\
\hline 2001 & 0.10 & -0.36 & -0.54 \\
\hline 2002 & 0.99 & -0.96 & 0.94 \\
\hline 2003 & 0.73 & -0.69 & 0.32 \\
\hline 2004 & -0.22 & 0.09 & -0.44 \\
\hline 2005 & -1.00 & -0.23 & -0.42 \\
\hline Validity & 0.48 & 0.52 & 0.63 \\
\hline
\end{tabular}

TABLE IV: CORRELATION BETWEEN NUMBERS OF TC OCCURRENCES AND PREVIOUS MONTH'S DMIS WITHIN A SEASON

\begin{tabular}{cccc}
\hline \hline TC Season & EDMI & WDMI & TDMI \\
\hline 1976 & 0.75 & 0.33 & -0.23 \\
1977 & 0.17 & -0.17 & -0.18 \\
1978 & 0.37 & 0.52 & 0.48 \\
1979 & 0.14 & 0.05 & -0.04 \\
1980 & 0.05 & -0.08 & -0.17 \\
1981 & 0.54 & -0.24 & -0.75 \\
1982 & 0.98 & -0.07 & -0.89 \\
1983 & 0.04 & -0.42 & -0.66 \\
1984 & -0.3 & 0.69 & 0.51 \\
1985 & -0.01 & 0.68 & 0.44 \\
1986 & -0.98 & 0.27 & 0.95 \\
1988 & -0.56 & -0.73 & -0.04 \\
1989 & 0.17 & 0.46 & 0.25 \\
1990 & 0.92 & 0.01 & -0.74 \\
1991 & 0.58 & -0.02 & -0.49 \\
1992 & -0.09 & 0.14 & 0.43 \\
1993 & 0.66 & -0.7 & -0.86 \\
1994 & 0.2 & 0.98 & 0.67 \\
1995 & -0.38 & 0.34 & 0.39 \\
1996 & 0.96 & 0.71 & -0.81 \\
1997 & -0.17 & -0.27 & 0.12 \\
& & &
\end{tabular}

\begin{tabular}{cccc}
1998 & -0.01 & 0.58 & 0.2 \\
1999 & 0.24 & -0.37 & -0.33 \\
2000 & -0.12 & -0.98 & -0.99 \\
2001 & -0.59 & 0.7 & 0.67 \\
2002 & 0.18 & -0.08 & -0.45 \\
2003 & -0.56 & 0.63 & 0.6 \\
2004 & 0.1 & -0.07 & -0.09 \\
2005 & -0.85 & 0.5 & 0.8 \\
Validity & 0.48 & 0.55 & 0.69 \\
\hline \hline
\end{tabular}

The correlations between Australian tropical cyclone occurrences and dipole indices (both individual and overall) were investigated and analysed in this study. A significant correlation has been found between previous month's dipole sea surface temperatures and following month's seasonal occurrences of tropical cyclones. These findings will add to the predictive tools which factors such as ENSO and Darwin pressure anomaly already provide. The prediction of occurrences of TCs is an extremely complex process, they typically provide very little forewarning. Thus, the more tools we have and the more we can integrate the performances of these tools, the better and more reliable will be our predictions. Furthermore, the data collection is not complex because the temperature anomalies are for two reasonably small areas in the Indian Ocean

\section{REFERENCES}

[1] W. M. Gray, "Tropical disturbance to cyclone transformation," in Proc. $11^{\text {th }}$ Tech. Conf. Hurricanes and Tropical Meteorology, Miami, Amer. Meteor. Soc., 1977, pp. 27-34.

[2] J. Namias, "On the causes of the small number of Atlantic hurricanes in 1968," Mon. Wea. Rev., 97, pp. 346-348, 1969.

[3] N. L. Frank, "Tropical systems - A ten year summary," in Proc. Preprints $11^{\text {th }}$ Tech. Conf. Hurricanes and Tropical Meteorology, Miami, Amer. Meteor. Soc., pp. 455-458, 1977.

[4] N. Nicholls, "A Possible Method for Predicting Seasonal Tropical Cyclone Activity in the Australian Region," Notes and Correspondence, Australian Numerical Meteorology Research Centre, Melbourne, Victoria, Australia, pp. 1221, 1979.

[5] K. Ashok, Z. Guan, and T. Yamagata, "Influence of the Indian Ocean Dipole on the Australian winter rainfall," Geophysical Research Letter, vol. 30, no. 15, pp. 1821, 2003.

[6] A. Pui, A. Sharma, A. Santoso, and S. Westra, "Impact of the El Niño-Southern Oscillation, Indian Ocean Dipole, and Southern Annular Mode on Daily to Subdaily Rainfall Characteristics in East Australia," Mon. Wea. Rev., vol. 140, no. 5, pp. 1665-1682, 2012.

[7] A. O. Fierro, and L. M. Leslie, "Links between Central West Western Australian Rainfall Variability and Large-Scale Climate Drivers," J. of Clim., vol. 26, no. 7, pp. 2222-2246, 2013.

[8] N. Nicholls, "Predictability of Interannual Variations of Australian Seasonal Tropical Cyclone Activity," Mon. Wea. Rev., 113, pp. 1144, 1985.

[9] P. A. Francis, G. Sulochana, and P. N. Vinayachandran, "Triggering of the positive Indian Ocean dipole events by severe cyclones over the Bay of Bengal," Tellus, 59A, pp. 461-475, 2007.

[9] R. A. Dare, and N. E. Davidson, "Characteristics of tropical cyclones in the Australian region," Mon. Wea. Rev., 132, pp. 3049-306, 2004.

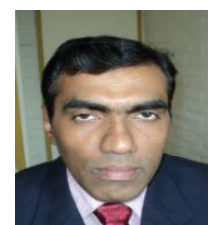

Kamal Kumar Saha was born and brought up in Bangladesh. He was graduated from Dhaka University, Bangladesh with Masters of Statistics in 1992. He also acquired Master of Business Administration (MBA) from University of Technology, Sydney, Australia in 2005. Currently he is studying for $\mathrm{PhD}$ accreditation in Central Queensland University, Australia.

This author worked in "Ac Nielsen Market Research Company" for one and half years on casual basis. During this current $\mathrm{PhD}$ program he worked with several academics as research assistant in various project at CQ University. His current research interest is statistical climatology. 
Mr. Saha is a life member of Statistical Association of Bangladesh a member Statistical Association in Australia.

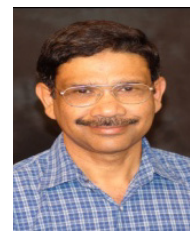

Saleh A. Wasimi is an associate professor and research coordinator at the School of Engineering \& Technology, Central Queensland University, Rockhampton, Australia $\mathrm{He}$ was born and brought up in Bangladesh and obtained his Bachelor and Master's degrees from Bangladesh University of Engineering \& Technology, Dhaka. He earned his PhD degree from The University of Iowa, USA. He worked in a number of universities as an academic, migrated to Australia in 1992 and has been working at his current university since 1993.

Professor Wasimi has authored seven books, published over fifty refereed articles, edited journals, organized several international conferences, and presented papers as keynote speaker in several conferences. Currently, he is the editor of Progress in Intelligent Computing and Applications.

Professor Wasimi's current research interests include stochastic processes, optimization, water resources planning and development, and climate change. Besides being an academic he has done consultancy work for many organizations in Australia, Bangladesh and USA. 